„, O R B I S L I N G UAR UM “, V O L UME 19, ISS U E 3

DOI: https://doi.org/10.37708/ezs.swu.bg.v19i3.6

\title{
THE USE OF STANDARD ALBANIAN LANGUAGE BY PRIMARY SCHOOL TEACHERS $^{1}$
}

\author{
Shpëtim ELEZI \\ University of Prishtina "Hasan Prishtina", Kosovo \\ E-mail: shpetim.elezi@uni-pr.edu \\ Violeta PLLANA ELEZI \\ University of Prishtina "Hasan Prishtina", Kosovo \\ E-mail: violeta@mileniumi3.net
}

\begin{abstract}
This paper investigates the level of standard Albanian use by primary school teachers for grades 1-5 in Kosovo as well as in the cities of Presheva and Bujanoc in Serbia. This paper investigates concrete situations and problems of standard Albanian and other varieties use in school. The research was conducted with a total number of 66 teachers in the form of a questionnaire and test on concrete problems of standard Albanian spelling norm. In order to have an example of a fourdimensional space, information on sociolinguistic factors, such as: work experience, region of origin, education, and gender of respondents were collected intentionally as important dimensions for a language. The research is of a descriptive nature and does not intend to provide assessments of a prescriptive nature nor take a stance on the investigated cases. Instead, in a more complete way, through the survey corpus, it intends to process the data statistically and present the current situation of standard Albanian use in its written form by primary school teachers. According to the research results, standard Albanian is not well mastered by the primary school teachers in Kosovo. However, based on the research results, in school we have a diglossic situation of different varieties use: standard Albanian, literary Gheg, dialectical (local) Gheg, which coexist depending on the situations of formal and informal communication that can occur in school, although in this domain of formal communication it is the high variety that is intended to be used.
\end{abstract}

KEYWORDS: Standard Albanian, Kosovo, Presheva, varieties, teacher, primary school, sociolinguistics

\section{Introduction}

School, together with the state administration and the media, constitute the main domains of standard language use, where the standard language is primarily used in its written form, and aspires to find use also in its spoken form. This situation is also evident in the school domain in Kosovo, where the use of that language variety is primarily implied which is conventionally called the standard variety, as the most neutral and appropriate term, that, according to the research, is now widely recognized and accepted among the teachers (respondents) who have been the focus of the research. This variety enjoys prestige, both as a language of pedagogical documentation and textbooks, and as a language that serves for the teacher-student communication, at all levels of the education system in Kosovo: at preschool, primary and secondary school, and university level. Thus, standard Albanian has gained the status of a language that represents the school and the education institutions in general. "The standard variety of a language is usually that variety that stands for the nation as a whole and for its most exalted institutions of government, education, and high culture in general" (Fishman, 1978, p. 45). Moreover, the school is also the main institution where standard language learning begins, and it plays an important role in the imposition and spread of this variety. The learning of the standard variety of Albanian or, more precisely, of the language system of this variety is also closely related to the formal education process, because it is there that the learning, spread, and further development of standard Albanian officially begins. The scholars agree that standard language can be learned and that its learning primarily occurs in schools, along with other institutions, such as the media, workplace, public life, etc., which also play a role in this regard. To this view, Fishman states "formal

\footnotetext{
${ }^{1}$ Part of this study, titled "The use of standard Albanian by primary school teachers" was presented in the 34th International Seminar on Albanian Language, Literature and Culture, held in Prishtina, Kosovo, from 17 to 29 August 2015.
} 
acceptance of the codified (standardized) variety is strengthened through intermediaries and authorities, such as the government, the education system, mass media, religious institutions, and cultural "establishment" (Fishman, 1978, p. 39). This information on standard language - learned through schooling and language pedagogical practice - is included in all standard language definitions, as a variety "learned in school" or "spread through school", etc. Trudgill (2000), for example, when describing standard English, refers to it as a variant that is learned in school. We find this element also in the definition of Ismajli on the standard Albanian language, which, according to him, marks "the common language variety for large spaces of written and oral communication, in the metadialect aspect, in public life, with a standardized and codified system, learned through schooling and language pedagogical practice, with a legitimacy created through the complex historical process in meetings of consensus and with institutional and traditional implementation" (Ismajli, 2005a, p. 33). According to Lloshi "school is the most important setting where society directly and intentionally intervenes to impose the literary norm" (Lloshi, 2011, p. 229). Also, according to a research by Munishi (2013), conducted through a survey with citizens in Kosovo, it turns out that 53\% consider school as the main standard language learning institution whereas 39\% list school along with the media. This is something that is generally accepted by sociolinguists. However, in spite of the great role that school has in learning and in using the standard variety, the problems of standard Albanian functioning and mastery on a not so good level should not be linked solely to teaching at school. The problem is far more complex than that, but this is not an issue that will be further discussed here. As far as the education system in Kosovo is concerned, learning and mastering the standard Albanian starts more intensively at the age of six and continues to be learned at all other education levels, and to some extent even in pre-school institutions, more as a communication skill in its spoken variant. This occurs because up to this age children in Kosovo have the Gheg dialect as their native language. Taking into account the changes in both dialects of the Albanian language, it is the elements of the Tosk that have been standardized, which makes the Gheg speakers feel more distant with standard Albanian and thus consider it harder to learn and use in formal situations.

Given the above, there is a close and twofold relationship between standard language and school: an institution where standard variety is learned and a domain where it is used the most. School imposes the standard form of a language to students who, before undergoing this process, for their communication needs, have learned spontaneously and practiced naturally a natural variety of theirs (their native language), acquired through imitation in the family and social settings where they were born and raised until the preschool age. Now, once they start school, children face a language variety different from their organic variety. This new variety for them is the standard Albanian, which children begin to learn due to their natural skills for languages as well as due to imitation and social contact. "One of the linguistic features of this variety is its artificial character" (Ismajli, 1991, p. 335). This feature does not only have to do with the fact that the formation of standard language is done arbitrarily and by using it at the wrong time and place, but also because its learning is imposed "forcedly", namely unnaturally, through various social mechanisms and, primarily, through school. Therefore, it is self-evident that whatever the overall level of education is, as such, it is manifested in the increase of the level of mastery of the standard language. For its part, the education system in Kosovo, in these decades of its operation, has experienced irregular and at times strange developments, by always developing in exceptional circumstances due to the general social and political developments through which Albanian society in Kosovo has gone through to date. Researchers, such as Ismajli (2005a) and Munishi (2013), describe in detail the political and social circumstances that have had direct or indirect implications on the policies for the standardization process of the Albanian language and in the level of its acquisition and spread in Kosovo. The Albanian school at all its levels has not developed in normal conditions in Kosovo even in the last two postwar decades, during which it has been and is still being attempted to adapt and draft different curricula to the point of pilot programs, at best, but which have never succeeded in being consistently consolidated. Therefore, the unsatisfactory level of standard Albanian in public communication in Kosovo should also be considered by taking into account these circumstances. This situation is a consequence of the school system during these years, since the standard Albanian was formed. Researchers, such as Bajçinca (2006), think that this poor situation of standard Albanian in Kosovo 
is, among other things, a consequence of an education system developed under unfavorable circumstances and under the great influence of Serbian language, especially in the $50 \mathrm{~s}$ and $60 \mathrm{~s}$ of the $20^{\text {th }}$ century. Similarly, according to Munishi (2013), the lack of spread of standard Albanian is a consequence of the insufficient imposition by institutions, schools, and the media. However, in addition to these and other sociolinguistic factors, such as the language setting, where the child learns the first variant of the spoken language, the primary school teacher education level, the television shows, and the affiliation to a certain social group, Paçarizi (2011) considers the lack of contact with source speakers of the variant on which the standard written language is based, as the most important factor. On the other hand, he also mentions psycho-linguistic factors that "are related to the processes of language production and understanding, then the psychomotor processes of acoustic realization of the mental concept, or the ability to transform visual signals into acoustic signals" (Paçarizi, 2011, p. 164). However, seen within the scope of this topic only, one can say that the situation in school generally reflects the situation of standard Albanian use. If we say that the education system is lacking, the same can be said in terms of quality of standard Albanian use. Of course, standard Albanian is learned also through the media, workplace, communication, and other circumstances, but school remains the main domain of its learning and use. This is also due to the fact that it is in school, as one of the main domains of the public communication where the motivation originates, the awareness is raised, and the idea for young people to learn and use standard Albanian is given, thus gaining the status of a prestigious variety compared to other dialectical and social language varieties, sometimes denying and mistakenly stigmatizing these natural varieties of children, of course having the good pedagogic intention that the learning, development and use of the standard Albanian, as a common linguistic variety, be done as best and as fully as possible in spoken and written communication. With regard to the role that the school and the education system have as the main subjects for standard language learning, Munishi (2013) says that any praise or criticism on the quality and level of standard language learning by the individual should be addressed to the school and the education system. "The high level of standard language learning is certainly the merit of the teachers who have taught the standard language to individuals, and any defect in standard language, if not a pathological defect, namely any type of aphasia, should be considered as a defect in a particular link of education system that has resulted in failure to learn the standard language" (Munishi, 2013, p. 77). Indeed, "a good system to raise the children is to put them in a stimulating environment where their natural capacity will be able to flourish" (Draçini, 2013, p. 240). But, according to Chomsky, for valuable social reasons, these skills not only are not taught to children, but schools designed to teach children obedience and conformism do exactly the opposite, "they prevent children's natural capacities from developing" (Chomsky, 2008, p. 172). From this point of view, the role of school in children is as important as it is delicate, but this is another issue and will not be further discussed here. Therefore, we will suffice with some thoughts about the process of learning Albanian language in school.

Researchers Ismajli (2005b) and Beci (2007) suggest that in the process of programming the knowledge for the mother tongue, in the process of drafting textbooks, and in the practice of teaching at school, it is considered that the Albanian language operates in variants, styles, and registers, each with a separate system of language tools and a special value, depending on the communication situations, the number of interlocutors, and the nature of the relationship with them, the purpose of the communication, etc. However, there are researchers such as Bajçinca (2006), Lloshi (2011) etc., who state the opposite of what was said above. Bajçinca thinks that only the standard Albanian language system should be taught in school, thus considering the above ideas as a tendency to corrupt or change the standard Albanian. While Lloshi, by identifying students at school, and also teachers who have a dialectal speech from a certain province, with their own habits and formation, says that "in our classrooms there is now no need to have teachers who do not master literary language, just as there is no need to get the diploma of the education faculty the students who even after 16 years of education ... are not able to shift from the dialect to the literary speech" (Lloshi, 2011, p. 230). Therefore, he adds that "there is a lot of work to be done ... for the literary Albanian to be heard inside the school walls" (Lloshi, 2011, p. 196). This conception, with all the good intentions it carries, not only does not sound good in the pedagogical aspect and is highly deniable with regard to the cultural and social aspect, but has already been stated in linguistics that a standard variety 
and other non-standard language varieties do not create contradictions, but complement each other in the language repertoire of a language entirety in situations with different communication functions. "Standard and other varieties up to the "pure" dialect complement each other in different planes and at different levels" (Ismajli, 2005b). Sociolinguists, such as R. Hudson, point out that "the teacher should certainly not aim at completely removing the non-standard variety from children. If this is clear to all concerned, children can learn to shift from standard to non-standard (and vice versa) according to circumstances, as happens in all diglossic communities" (Hudson, 2002, p. 248). This occurs also because, as psycholinguists such as Paçarizi (2011) emphasize, until the age of six children have already perfected their native language. Therefore, any other language they learn after this age is counted as the second language, which they will never succeed in acquiring to the extent that they use it as a language of emotions, language of fairy tales, and intimate language. According to him, for children in Kosovo standard language is not the language they have learned by listening to it permanently. So, even when they come to school, they do not learn the spoken standard, but the written standard, which they experience as a language different from what they have learned up to that age at home and thus identify the standard Albanian only with the written form (for more detail see Paçarizi, 2002, p. 109-136). Further, Ismajli (2005b) says that it is necessary to seek and encourage the use of dialectical and substandard expression, not only because it is experienced as a natural expression but also for basic pedagogical reasons: it stimulates the need for careful language, which is essential to the standard. "It is therefore necessary for the standard Albanian language to be further learned in school not by denying the different varieties that the children have brought with them. Instead, it should be learned as a separate "code", easily distinguished: children should be told that resources, function, and the implementation of the standard language are different from those of the varieties they already know... Through this we help expanding the communication skills of children on different Albanian varieties, including the expansion of standard Albanian acquisition" (Ismajli, 2005b). This view was also expressed in the meeting of the Interacademic Council of Albanian Language, which consists of the Academy of Sciences of Albania and the Academy of Sciences and Arts of Kosovo. In the second item of the agenda, where the following issue was discussed: "Standard Albanian and School", as the 8th proposition the following is given: "In schools attention should be paid to the cultural diversity and the dialectal diversity of Albanian, so as not to create space for stigmatization of any Albanian variety" (Interacademic Council of Albanian Language, 2014). Likewise, Munishi (2015), besides the need to revise and enrich with a national consensus the standard Albanian corpus with elements of other spoken Albanian varieties, adds that "the learning plan should focus not only on learning the norm of standard Albanian by students and other standard Albanian users, but also on learning other Albanian varieties" (Munishi, 2015, p. 172). In terms of the standard Albanian relation to other codes, he promotes a relatively liberal and egalitarian policy in accordance with the cultural diversity as a social value contrary to the monolingual approach, and suggests that the use of these varieties of Albanian is done in accordance with the functional adequacy. Munishi (2015) thinks that these actions in the field of language planning and policy would contribute to strengthening the vitality of the Albanian language, to expand its functionality, to be accepted and implemented by all Albanians, and thus to face global and regional challenges of this millennium. According to Ismajli (2005b), the two traditionally developed roles of mother tongue teaching should be balanced: teaching based on the linguistic and grammar code that considers the written Albanian as the best expression of the standard Albanian and teaching focused on speaking, on the production of messages, which takes into account the perspectives and results of sociolinguistic, psycholinguistic, and functional studies, which is not limited to grammatical rules only, but gives space to creative abilities and potentials, in-class verbal activity, spontaneity. It is precisely in this spirit, as a theoretical knowledge and as a practice of use, that the Albanian language can be imposed and taught to children in school, because, after all, it is the communication as a function of language that it is primary. It should also be taken into account that Albanian language teaching in the education system in Kosovo is thought as the bearer of such activities as: listening and speaking; reading and writing - skills that are important not only for learning the Albanian language course but also that through them other subjects in school are learned as well as for "the literacy of the population and the transmission of traditional values, literature, and inherited culture, knowledge, 
(i.e., mother tongue teaching - my note) aims to prepare individuals to exercise the function of institutionalized communications within and outside the national community. It is therefore necessary not to forget the language varieties associated with these functions. In all variants there must be a mastery of the chosen oral Albanian in place. According to Ismajli (ibid.), standard and correct Albanian is required in written activities, whereas in oral activities the most distinguishing elements can be presented, talked about, and practiced.

Given all the above, the teacher plays the essential role as one of the central components in the learning process alongside curricula and textbooks, thus forming the triangle textbook-teacher-student, that naturally represent three language varieties. Teaching methodologists call the role of the teacher very important in this whole process. According to Lloshi (2011), the teacher who lectures in the classroom to give knowledge to students, necessarily teaches them the language, through which they express that knowledge and the culture of discourse. The learning outcomes in general and the learning of the Albanian language in particular depend also on the effectiveness of the methods used by the teacher in the classroom. However, in order to give students the desired effect, these methods should be applied by a competent teacher in their field of expertise. Therefore, there is no doubt that such a teacher, who first of all proves to be competent in quality and language performance and possesses the didactic component of teaching, has an overall impact on students and constitutes a fundamental factor for qualitative learning of (standard) Albanian language in its written and spoken form. According to Munishi (2013), teachers, along with the TV announcers, are considered as the best transmitters and spreaders of the standard language spoken norm. Of course, students of the 5-year primary school, in addition to learning through various global methods, often learn the written form of the language in a photographic way by seeing it in writing and the spoken form by imitating primarily their teachers during their speech act. This occurs because "the speech act forms an entirety in which language and speech are merged into one - that language as a system and the speech act are two sides of a single phenomenon: knowing a language means knowing the system as well the speech act" (Beci, 2007). The teacher is also a model to be followed by the students in both the written and oral practice of the standard language. However, what model does the primary school teacher in Kosovo provide? What is their level of knowledge and use of standard Albanian? So far, the answers to these questions have often come in the form of unfounded statements in concrete field research. Islamaj (2004) finds that "the language culture of our teachers, who work at universities, as well as in secondary and primary education, is unsatisfactory, not to say bad in the broader scope. This is especially true for the linguistic expression that characterizes the teaching process and the public presentation of this intellectual class" (Islamaj, 2004, p. 77). To this end, she says that "the causes are numerous, both objective and subjective, but much more subjective (ibid., p. 77). Even Bajçinca (2007), among other things, speaks of a low degree of preparation of teachers in general and Albanian teachers in particular, especially in the field of language culture. An insufficient degree of knowledge and implementation of the standard Albanian is also found by the Interacademic Council of Albanian Language, in the discussions and proposals on the second issue of the agenda: "Standard Albanian and School", where, among other things, it is proposed to "train language teachers in four-year periodic courses" (Interacademic Council of Albanian Language, 2014). However, although this research in the field of sociolinguistics deals with the problem of standard Albanian use by teachers, because the school system is one of the main domains of standard varieties learning and spread, Hudson (2002) draws our attention that the language form used in class should not be confused with other information that may seem the most important in the learning process. Therefore, based on this view, one should not prejudge the linguistic form to such an extent that it affects the creation of misconceptions about the ability of teachers, their other skills, and their general level of teaching. So, here the qualitative level of the standard Albanian use will be investigated, but without prejudice to their other skills, such as pedagogical, communicative, etc. Likewise, based on the measurements how standard their language is, it would be wrong to draw the conclusion that all teachers have low language competency because, beyond that, they may have "communication competency", a term coined by Dell Hymes (1971) that includes the necessary knowledge of the speaker or the listener, and which has a wider basis than the "language competency" of the Chomskyan linguistics. On the other hand, Basil Bernstein distinguishes two 
very general language "codes", which he calls the "restricted" code and the "elaborated" code. According to this theory, the latter code, the elaborated one, is the one that is needed in school, where it is important to be able to express oneself accurately and clearly. Nevertheless, the competencies that children have are uneven because they come from different social settings (Bernstein, as cited by Hudson, 2002, p. 246). So, this research does not prejudge the learning outcomes in the classroom, because it happens that teachers, even though they perform poorly in standard Albanian, be such resourceful teachers that students receive the relevant information quite well. According to Hudson (2002), it must not be assumed that teachers with low level of standard have low success rates in the teaching process. Such an impression on teachers would be just as wrong as comparing children who have a way of speaking that initially gives an unfavorable impression. It is the information what matters in the end. By creating our impressions on teachers only on the basis of their standard Albanian mastery, we would neglect other factors that influence the teaching process. This is not what we are claiming here. So, it would be wrong to think that all teachers who speak in varieties or have non-standard pronunciation are poor and unsuccessful teachers. They may not teach well the standard language to children, namely the language system of this variety, an important goal for them to achieve, but they can still be successful teachers because they possess a range of other components that relate to their personality and the teaching process in general.

\section{Research Questions}

This research is more of a descriptive character because, primarily, it describes the linguistic situation regarding the standard language use by the teachers of various schools in Kosovo. The aim was not to provide prescriptive assessments, nor to take a stance on the investigated cases. Instead, in a more complete way, through the survey corpus, it intends to process the data statistically and present the current situation of standard Albanian use in its written form by primary school teachers. Through this research, answers were given to the following questions:

Which Albanian variety is used by the teachers in class/school when communicating with students?

Which of the varieties is used most often when communicating with students and why?

Is standard Albanian used for learning lessons only or other topics too?

Is standard Albanian used only in Albanian language classes or in other classes too?

The answers to these questions have led to the research results through which was determined the level of the standard Albanian and other varieties use by the primary school teachers for grades 1-5 and the teachers' language competency level in standard Albanian.

\section{Methodology}

This paper investigated the linguistic situation of the standard Albanian use by the primary school teachers for grades 1-5. Through empirical sociolinguistic measurements, this research, which was conducted in the field in May 2015, investigated concrete situations and problems of standard Albanian and other varieties use in school. The research was conducted in the form of a questionnaire and test on concrete problems of the written norm of standard Albanian with a total number of 66 teachers in some of the primary schools in Kosovo as well as in Presheva and Bujanoc, which are Albanian-majority cities southeast of Serbia where standard Albanian language is learned in school. This number of people was included to facilitate the interpretation of the results. The schools and the research samples were selected randomly. Out of the 66 respondents, 24 respondents from both public and non-public schools were surveyed in Prishtina, 5 respondents in Gjilan, 6 in Kamenica, 3 in Kaçanik, 2 in Kllokot, whereas in Viti, Novobërda, Shtërpca, and Hani i Elezit by one respondent each, in Presheva 12 and in Bujanoc 10. Out of these, with regard to their level of education, 44 teachers have completed Higher Pedagogical School (HPS - 2-year program), 12 have a bachelor's degree, and only 8 have a master's degree; 2 did not state their level of education. With regard to their work experience, it turns out that most of them had more than 10 years of teaching experience. As for the gender, 49 were female teachers whereas 17 male teachers. As far as the origin is concerned, 27 came from rural areas whereas 35 came from the urban areas; 4 did not state their origin. In order to have an example of four-dimensional space, information on sociolinguistic factors, such as work experience, region of origin, education, and gender of the respondents, were collected as important dimensions for the language. The research was carried out in compliance with the ethical guidelines for 
fieldwork. Thus, respondents were informed that the survey was being conducted for study purposes of a sociolinguistic character and that the information received from them will be used only in the context of this study and will remain confidential, as they were able to remain anonymous by not giving their name, but only other relevant data. The questionnaire, consisting of 9 questions, was designed in three parts, taking into account three different purposes: in questions 1 to 7 of the closed-ended type it was required to provide an opinion and stance of the teachers regarding the situations and functions of the standard Albanian and other varieties use in school; question 8 required to choose between the correct and incorrect option of 10 individual examples with grammatically incorrect forms, ranging from those that can be considered as easy and moderate to those that are of a more difficult nature to solve. Question 9 consisted of a text with 49 linguistic errors (mostly of phonetic and morphological nature and less of a syntactic character), which the respondents had to correct and adapt according to the standard Albanian rules. The respondents responded in writing within the specified time.

\section{Results and analysis}

\subsection{Interpretation of the results for questions $1-7$}

Through the first questions of the questionnaire (questions 1-7), we aimed at getting the teachers' opinion on how often, when, where, and what for they use standard Albanian when communicating with students; what their attitudes towards standard Albanian are; and whether they use any other variety in their school communication. In the first question: Do you use standard Albanian when communicating with students? - 83\% (55 respondents) answered: YES, 15\% (10) chose the option: NO, whereas 2\% (1) did not answer the question.

This high percentage was confirmed by the second question. When asked about the setting where they use standard Albanian the most when communicating with students, $86 \%$ (57 respondents) chose the option: in any school setting, 12\% (8) responded: only in the classroom, no one chose the option: I do not use it in any school setting, and 2\% (1) did not answer the question. A large number of respondents, namely $61 \%$ of them (40 respondents) chose the option: regularly, when asked about how often they use standard Albanian when communicating with students, 26\% (17) responded: generally, 12\% (8) chose the option: averagely, and 1\% (1) did not answer the question; No one chose the options: sometimes or never.

When asked about what kind of topics they use standard Albanian for the most when conversing with students, 77\% (51) of them chose the option: for learning lessons and free topics, while only 9\% (6) chose the option: for learning lessons only. The same small percentage of $9 \%$ (6) consisted also of those who stated that: they always speak in dialect with the students, while none of them chose the option: we speak in dialect for free topics, and 5\% (3) of respondents did not answer the question.

Similarly, a high percentage of $77 \%$ (51) also responded to the question of whether they use standard Albanian: in all classes of any subject, while only 17\% (11) said they use it: more in Albanian classes and less in classes of other subjects, $1.5 \%$ (1) chose the options: in Albanian language classes only and in classes of other subjects I speak in dialect, and 3\% (2) respondents did not answer the question.

Interestingly, their responses to the sixth question, namely the options they chose, contradict what they have said above with regard to the level of standard Albanian and other varieties use by the teachers when conversing with students in the school setting. For example, when asked which language variety the student understands more easily, 65\% (43) of them chose the option: sometimes in standard and at other times in dialect as needed, while only $23 \%$ (15) chose the option: in standard language. The option: in dialect language was chosen by $4 \%$ (3), while $8 \%$ (5) chose not to answer at all. Further, when asked about the level of difficulty of using standard Albanian when communicating with students, in the statement: Communicating in standard Albanian for me as a teacher is - they chose to answer in between the options: easy $47 \%$ (31 respondents) and not so easy $29 \%$ (19). The communication in standard Albanian was considered as very easy by only $9 \%$ (6) of them and as not so difficult by $8 \%$ (5); only $1 \%$ (1) considered it as difficult and none of them as very difficult. But, as we will see below, these data contradict with how the respondents answered when tested on the individual examples in the eighth question and when correcting the text with errors in the ninth question of the questionnaire.

\subsection{Interpretation of results for question 8}


As noted above, the teachers were tested with 10 individual examples, for which they had to give the correct spelling options in standard Albanian. The examples provided in the questionnaire reflected different difficulty levels, which was also reflected in the overall results.

With regard to the first incorrect example: ai do të punon, 48 respondents or $73 \%$ gave an incorrect answer whereas 18 of them or $27 \%$ gave the correct answer;

For the singular form of the first person: un, 52 or $79 \%$ gave a correct answer whereas 14 of them or $21 \%$ gave an incorrect answer;

With regard to the variant of the Gheg infinitive: me lexu, 51 of them or $77 \%$ gave an incorrect answer and only 15 respondents or $23 \%$ gave the correct answer.

With regard to the Gheg form with the non-rhotic /n/ of the word syni, 56 of them or $85 \%$ gavea correct answer whereas 10 of them or $15 \%$ gave the incorrect answer;

Further, 46 of them or $70 \%$ gave an incorrect answer to the plural form of the word student (disa student) whereas 20 of them or $30 \%$ gave the correct answer (disa studentë);

With regard to the incorrect form of the indefinite pronoun: gjithëqka, 39 of them or $59 \%$ gave an incorrect answer whereas 27 of them or $41 \%$ gave the correct answer;

With regard to the correct form of the noun tenxhere, 36 respondents or 55\% correctly considered it as correct, as was provided in the survey, whereas 30 of them or $45 \%$ gave an incorrect answer;

With regard to the ungrammatical form of the definite plural: miqët, 35 respondents or $53 \%$ gave an incorrect answer whereas 31 of them or $47 \%$ gave the correct form: miqtë;

With regard to the incorrect form of the verb: kam ndejtur, 47 respondents or $71 \%$ gave an incorrect answer where as 19 of them or $29 \%$ gave the correct answer;

With regard to the last example in this part of the questionnaire, namely the incorrect plural form of the noun: shkopinjë, 55 of them or $83 \%$ gave an incorrect answer whereas only 11 of them or $17 \%$ gave the correct form of the plural: shkopinj.

In general, for these 10 examples, 57\% answered incorrectly whereas $43 \%$ answered correctly.

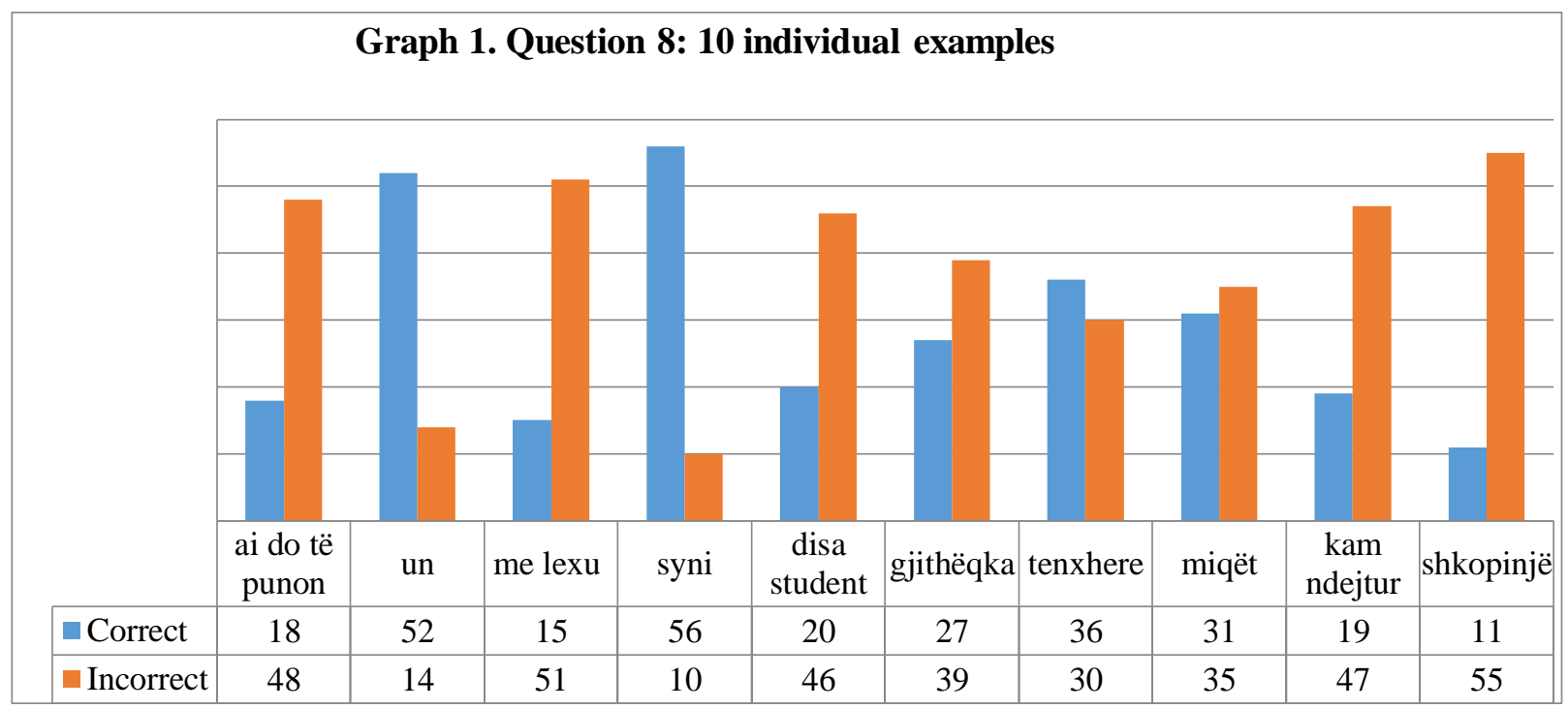

As a conclusion to this part, for these 10 examples, it can be concluded that some of them, especially the following incorrect grammatical forms: ai do të punon (73\% incorrect), disa student (70\% incorrect), kam ndejtur (71\% incorrect), shkopinjë (83\% incorrect), and the Gheg infinitive: me lexu (77\% incorrect), given that they present a high percentage (over 70\%) of incorrect answers, indicate a very low level of language competency of the respondents, and consequently a low level of teachers' competency of standard Albanian. On the other hand, some other cases, which are considered as easier by the difficulty level, such as un and syni, since there is a high percentage (over 70\%) of the correct answers, reflect a higher level of language competence of respondents, and consequently a higher level of teachers' competency in standard 
Albanian. But even here, given that they are words of high frequency in the primary school domain and in general, even that small percentage of inaccuracy (un: $21 \%$ and syni: $15 \%$ ) proves the opposite, i.e. the low language competency of the teachers surveyed. Other cases, such as: gjithëqka (59\% incorrect), tenxhere (45\% incorrect), miqët (53\% incorrect), that are average as far as the percentage of accuracy and inaccuracy is concerned - in fact, there is a tendency towards the latter, as is seen by the overall result (57\% incorrect) - indicate the same conclusion as pointed above, namely, an overall low language competence of the primary school teachers surveyed for grades 1 to 5 .

\subsection{Interpretation of results of the text with errors (question 9)}

The text given in the questionnaire contained a total of 49 spelling errors that reflect the four spelling principles of standard Albanian: phonetic, morphological, historical-traditional, and lexicosemantic. The survey results of the 66 teachers were classified into levels, according to a personal assessment model from my work with students. This was done for the measured survey data to present as accurately as possible the language competency of the teachers surveyed. Thus, four levels of respondents were distinguished. Those who committed:

1. $0-3$ errors - very good competency;

2. $4-6$ errors - good competency;

3. 7-9 errors - fair competency;

4. more than 10 errors - poor competency.

I considered the first two levels as acceptable, demonstrating a good level of language competency, while the latter two as not good levels, demonstrating a fair or poor language competency.

\section{Graph 2. Results of correction of text containing 49 errors}

๑. 0 - 3 errors (4) $\square$ B. 4 - 6 errors (9) $\square$ C. 7 - 9 errors (8) $\square$ D. more than 10 errors (45)

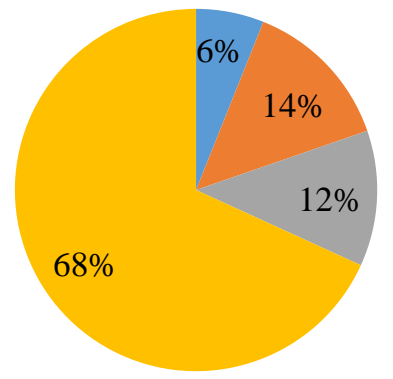

Overall, it appears that only 13 teachers or $20 \%$ belong to the first two levels with good language competency ( 9 respondents) and very good language competency (4 respondents), whereas 53 or $80 \%$ belong to the last two levels with fair or poor language competency. It should also be noted that no teacher committed zero errors, nor one or two errors. Out of the total number of the respondents, 45 teachers or $68 \%$ committed more than 10 errors, and out of these 45 respondents, 12 teachers or $27 \%$ committed more than 20 errors, which shows a very low level of language competency, whereas 33 respondents or $73 \%$ committed from 10 to 19 errors, which also reflects low language competency.

\subsection{Comparison of Public and non-public schools}

To see more precisely the level of teachers' language competency, a separate analysis was conducted to the data taken from two Prishtina schools: one public and the other non-public (private). 
„, O R B I S L I N G UAR U M “, V O L UME 19, IS S E 3

DOI: https://doi.org/10.37708/ezs.swu.bg.v19i3.6

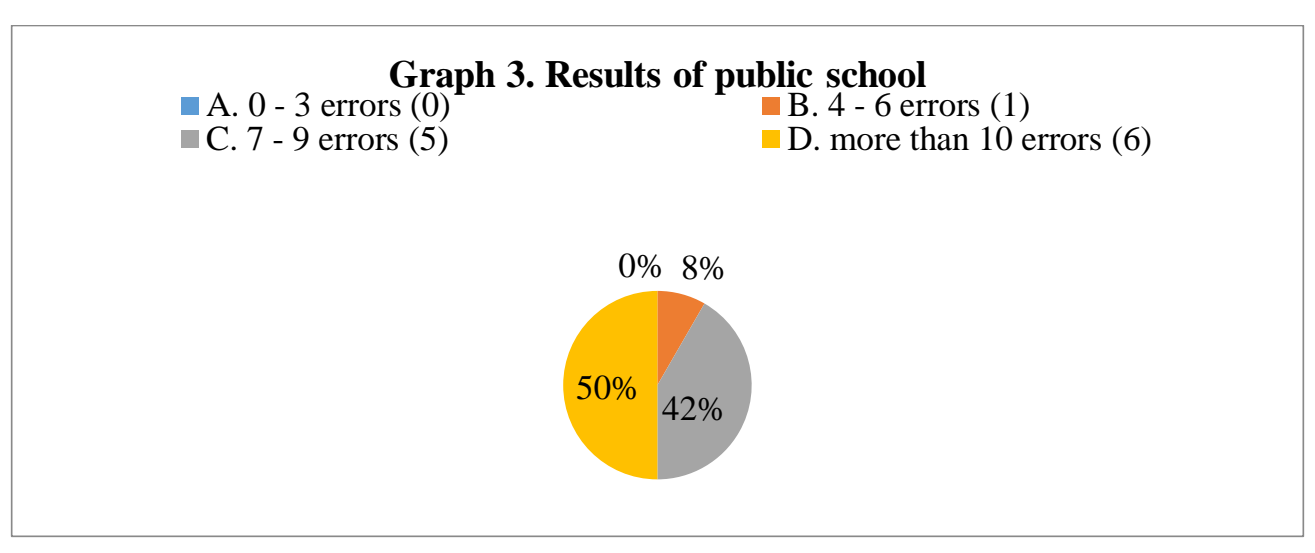

Taking the four levels set out above as a benchmark, out of the 12 public school respondents, none of them (0\%) belong to the first level with $0-3$ errors; only 1 respondent or $8 \%$ belongs to the second level with $4-6$ errors; 5 respondents or $42 \%$ belong to the third level with $7-9$ errors; and 6 of them or $50 \%$ belong to the fourth level with more than 10 errors committed.

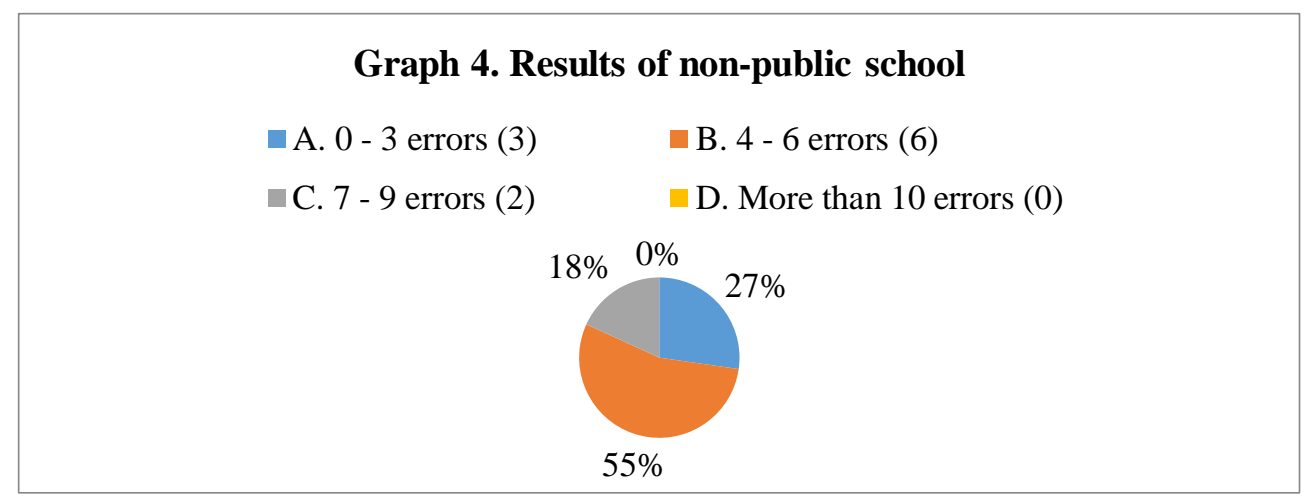

On the other hand, with regard to the non-public (private) school, the results for all the 11 respondents are as follows: 3 respondents or $27 \%$ belong to the first level with $0-3$ errors; 6 respondents or $55 \%$ belong to the second level with 4 - 6errors; 2 respondents or $18 \%$ belong to the third level with7 9 errors, whereas there are no respondents with more than 10 errors in this non-public primary school. When we compare these data between the two schools, it turns out that non-public school teachers demonstrate much higher competency than public school teachers. Only 1 respondent, accounting for $8 \%$ of the total public school, belongs to the second level with good competency, unlike non-public school respondents, of whom 9 or $82 \%$ of the total group belong to the first two levels with good and very good language competency. The largest number of public school respondents, namely 11 teachers, accounting for $92 \%$ of their group, belong to the last two levels with fair and poor language competency, while only 2 respondents, accounting for $18 \%$ of the non-public school teachers, belong to the third level with fair language competency. This group has no teachers who belong to the fourth level with more than 10 errors. Based on this data analysis, it can be said that teachers of non-public school demonstrate a much higher language competency than their public school counterparts. It can also be understood that the result of the non-public school respondents raises the overall level of the survey results, because out of the total number of 13 teachers or $20 \%$ who belong to the first two levels with good and very good language competency, 9 of them are from the non-public school whereas only 4 are from all the public schools of other centers where the survey was conducted.

4.5. The case of the Gheg infinitive of the type "me punu(e)"

It is worth mentioning the search findings with regard to the use of the Gheg infinitive of the type me punu(e). Out of the four instances given in the text: me lexue, me luejt, me dalë, me organizue, the results 
of their substitution with either the forms of the subjunctive or the infinitive of the type për të lexuar are as follows:

\section{Graph 5. Results of the Gheg infinitive substitution}
A. It was not changed at all (25)
B. It was changed in 1 instance (6)
C. It was changed in 2 instances (4)
$\square$ D. It was changed in 3 instances (4)
E. It was changed in all 4 instances (27)

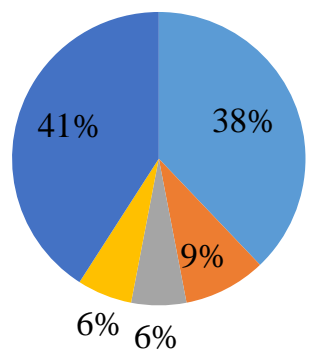

a. It was not changed at all by 25 respondents or $38 \%$

b. It was changed in one instance by 6 respondents or $9 \%$

c. It was changed in two instances by 4 respondents or $6 \%$

d. It was changed in three instances by 4 respondents or $6 \%$

e. It was changed in all four instances by 27 respondents or $41 \%$

Overall, as far as these data are concerned, the results are 50/50, which means that half of the teachers have adapted the Gheg infinitive to the standard Albanian forms (the standard subjunctive or the standard infinitive) whereas the other half has considered the Gheg infinitive as a verb form of standard Albanian.

\section{Conclusions}

As mentioned above, school is one of the most important domains of the public use of Albanian, and, indeed, language in school means above all the use of its standard variety. However, this research proves that there are cases of other Albanian language varieties use, which in the teachers' discourse coexist with the standard Albanian. Therefore, it can be concluded that, based on the research results, in school we have a diglossic situation of different varieties use: standard Albanian, literary Gheg, dialectical (local) Gheg, which coexist depending on the situations of formal and informal communication that can occur in school, although in this domain of formal communication it is the high variety that is intended to be used. This phenomenon of code coexistence and code-mixing that depends on the communication situations, which can be seen as an integral part of a language continuum within the same language, is noticed not only in terms of what the respondents stated but also in the investigation of the dialectal elements and forms, such as, for example, the use of the Gheg infinitive and the Gheg future. Such language mixing of the standard language with the non-standard varieties are often manifestations of style shifting, driven by the need to adapt to the audience in school to which the communication is related, according to what A. Bell (1984, p. 1991) calls "audience-design", that is, accommodating the language to the audience. Teachers' language competency investigated quantitatively and qualitatively, turned out to be of a low linguistic level. In general, the following conclusions emerge from this research:

- With regard to the amount and the frequency of standard Albanian use, it appears that teachers always use it when conversing with students in all school settings, for learning lessons and free topics in classes of any subject;

- Nevertheless, it has been seen that most, to be better understood, speak to students sometimes in standard and at other times in dialect as needed; 
- With regard to the level of difficulty/ease of use, standard Albanian is, according to them, an easy variety to use;

- However, the research results prove the opposite: the use of other Albanian varieties and the poor language performance;

- As for the quality of use, despite their statements that they use standard Albanian the most, the results show that in terms of quality the standard Albanian use leaves much to be desired;

- The level of language competency differs significantly between the public and non-public school teachers, also due to the recruitment process and the teachers' educational level;

- The low level of language competency also results from the inadequate teachers' education. Most of them (44) have completed High Pedagogical School, 12 hold a bachelor's degree and only 8 of them have obtained a master's degree.

\section{REFERENCES:}

Bajçinca, I. (2006)

Beci, B. (2007)

Bell, A. (1997)

Chomsky, N. (2007)

Draçini, Rr. (2013)

Fishman, J.A. (1978)

Hudson, R.A. (2002)

Interacademic Council

for the Albanian

Language (2014)

Islamaj, Sh. (2004)

Ismajli, R. (1991)

Ismajli, R. (2005a)

Ismajli, R. (2005b)

Lloshi, Xh. (2011)

Munishi, Sh. (2013)

Munishi, Sh. (2015)

Paçarizi, Rr. (2011)

Trudgill, P. (2000)
Shqipja standarde dhe probleme rreth saj. (Lecture with the Albanian language teachers in Scandinavian countries, 11-12 May 2006, Landskrona, Sweden). Available at: https://orientalizmi.wordpress.com/2013/04/13/shqipja-standarde-dhe-problemete-saj/ [Accessed August 20, 2021].

Probleme të mësimit të gjuhës amtare në shkollë. (Lecture with the Albanian language teachers in Scandinavian countries, 15-16 May 2007, Landskrona, Sweden). Available at:http://s2.e-monsite.com/2009/12/10/97618954problemet-te-mesimit-te-gjuhesamtare-ne-shkolle-bahri-beci-pdf.pdf [Accessed August 20, 2021]

Language Style as Audience Design. Sociolinguistics A Reader. Edited by Nikolas Coupland and Adam Jaworski. New York: St. Martin's Press, p. 240-250.

Gjuha dhe problemet e njohjes. Tirana: Toena, $206 \mathrm{p}$.

Përftimi i shqipes përmes dialektit dhe standardit. Shkodra: Fiorentia, 328 p.

Sociologija jezika. Sarajevo: Svjetlost, 282 p.

Sociolinguistika. Tirana: Dituria, 304 p.

The meeting of the Interacademic Council of Albanian Language was held in Tirana. (Co-Chairs: acad. Jani Thomai and acad. Rexhep Ismajli). Held on 20 June 2014 in Tirana. Available at: http://www.ashak.org/?cid=1,2,471 [Accessed August 20, 2021] Gjuha, ligjërimi dhe fjala. Prishtina: Prishtina Institute of Albanology, 302 p.

Gjuhë dhe etni. Prishtina: Rilindja, 450 p.

Gjuhë standarde dhe histori identitetesh. Tirana: Academy of Sciences of Albania, 491 p.

Për zhvillimet në fushën e gjuhës standarde. (Lecture held in the Conference of Albanian language teachers, 10-11 March 2005, Landskrona, Sweden). Available at: https://www.forumishqiptar.com/threads/49982-Akademik-REXHEP-ISMAJLI-

Zhvillimet-e-gjuh\%C3\%ABs-standarde [Accessed August 20, 2021]

Shqipja, gjuhë e hapur dhe dinamike. Tirana: Onufri, $327 \mathrm{p}$.

Probleme të shqipes standarde në Kosovë. Prishtina: ZeroPrint, 226 p.

Shqipja në epokën e globalizimit. Prishtina: ZeroPrint, p. 187.

Shqipja standarde në parametrat psikolinguistikë. Prishtina: Kosova Pen Center, 287 p.

Sociolinguistics - An Introduction to language and Society. London: Penguin Books, $228 \mathrm{p}$. 